\title{
Gustav Mie: the man, the theory
}

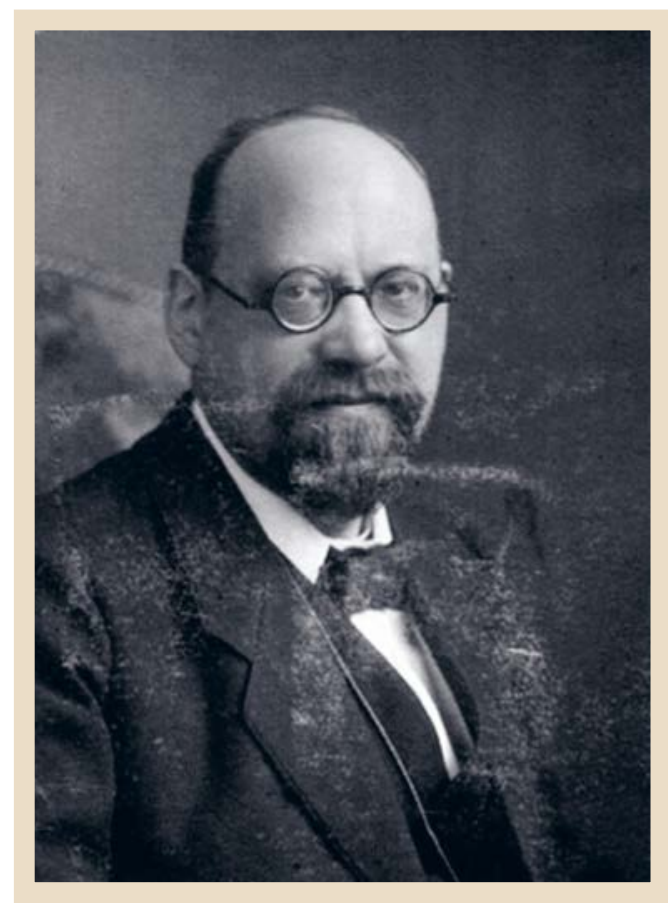

By Brian STOUT* and Nicolas BONOD

* brian.stout@fresnel.fr

Gustav Mie was a German scientist who published a rigorous electromagnetic scattering theory by a spherically shaped particle in 1908, but which only began to attract attention some fifty years later. How then did Gustav Mie, who was initially attracted to science by his interest in mathematics and mineralogy, publish a 'hidden gem' that now shines so brightly over physics?

https://doi.org/10.1051/photon/202010122

This is an Open Access article distributed under the terms of the Creative Commons Attribution License (http://creativecommons.org/licenses/by/4.0), which permits unrestricted use, distribution, and reproduction in any medium, provided the original work is properly cited.

$\mathrm{W}$ ere you asked to name famous $20^{\text {th }}$ century physicists, it is rather unlikely that Gustav Mie would be near the top of your list. Nevertheless, starting from the late 1940's, Mie's 1908 opus [1] on the scattering of light scattering by a spherical particle has played an important role in physics and technology. So who was Gustav Mie and how did a single publication authored by him in the early $20^{\text {th }}$ century, treating a 19th century problem, become an entire methodology, most often referred to simply as 'Mie theory', with literally tens of thousands of citations in the $20^{\text {th }}$ and $21^{\text {st }}$ centuries?
Gustav Mie (Sept. 29 ${ }^{\text {th }} 1868-$ Feb. 13 $\left.{ }^{\text {rd }} 1957\right)$ grew up in Rostock, a German city along the coast of the Baltic sea, in a family of protestant pastors. Although initially set to follow the family tradition, his interests turned to the natural sciences and mathematics during his high school years. His university education was carried out between his native city of Rostock and Heidelberg with a noted emphasis on mathematics and geology with physics and chemistry falling rather to the background of his formal education.

In 1890, Mie passed the State Examination for Mathematics and Physics that grants access to

\section{BIOGRAPHY}

\begin{tabular}{l|lll|}
\hline & $\mid$ & $\mid$ & $\mid$ \\
1868: & 1901: & $1902-1917:$ & $1908:$ \\
Birth at Rostock, & Wedding & Professor at the university & Publication of his theory \\
Germany & with Berta Hess & of Greifswald & Passing light scattering
\end{tabular}


the higher teaching profession. Mie spent weeks preparing his dissertation in physics and his examinator, Otto Lehmann, was highly impressed by Mie's developments on induction and the construction of dynamo electric machines, but this left him only 24 hours to write his entire dissertation in mathematics which was evaluated with quite less praise. After his doctoral thesis, defended in Karlsruhe in 1891, "On the fundamental Principle of the Existence of integrals of Partial Differential Equations", his prospects for a scientific career seemed slim and in the summer of 1892, Mie accepted a teaching position in a private school at Dresden. A turning point in Mie's life came when he sent his dissertation to his former examiner, Otto Lehamn, a German physicist and crystallographer, considered as the first physicist to have studied liquid crystals. Otto Lehman offered Mie an assistantship at the Technical University of Karlsruhe which embarked Mie on a career as a distinguished physics professor that spanned two world wars and considerable social upheavals.

Since mathematics and mineralogy were Mie's preferred university subjects, his physics education was largely auto-didactic, and he made good use of his first years of teaching a practical physics course in Karlsruhe to improve his mastery of experimental techniques. Henrich Hertz's renowned experiments on the propagation of electromagnetic waves, performed

\section{MORE THAN MIE}

Although Mie learned of and cited Maxwell Garnett's (1904 and 1906) work on metal colloids [5], it appears that he was unaware of Lorenz's 1890 (non-electromagnetic) theory of light scattering by lossless spheres [6]. In 1890, Maxwell's equations were not yet as enshrined as they are today, and Ludvig Lorenz based his theory on a 'model-free' set of equations, which, for non-magnetic media, were mathematically equivalent to Maxwell's light propagation formulas. There are certain similarities here to Augustin Fresnel's reflection-transmission coefficients which were also derived on general principles for lossless media, but which were later readily generalized to include dispersive media in the context of Maxwell equations. Since L. Lorenz's expressions for the renowned scattering coefficients in the context of dispersionless scatterers are the same as those obtained by Mie in his study of dispersive scatterers, a number of modern authors now refer to 'Lorenz-Mie' theory in the interest of historical justice. In 1909, Peter Debye published a work on light scattering which included analytical expressions for the optical forces on the sphere, so one also encounters references to 'Lorenz-Mie-Debye' theory.

\section{The World's Most Influential Optoelectronic Exhibition}

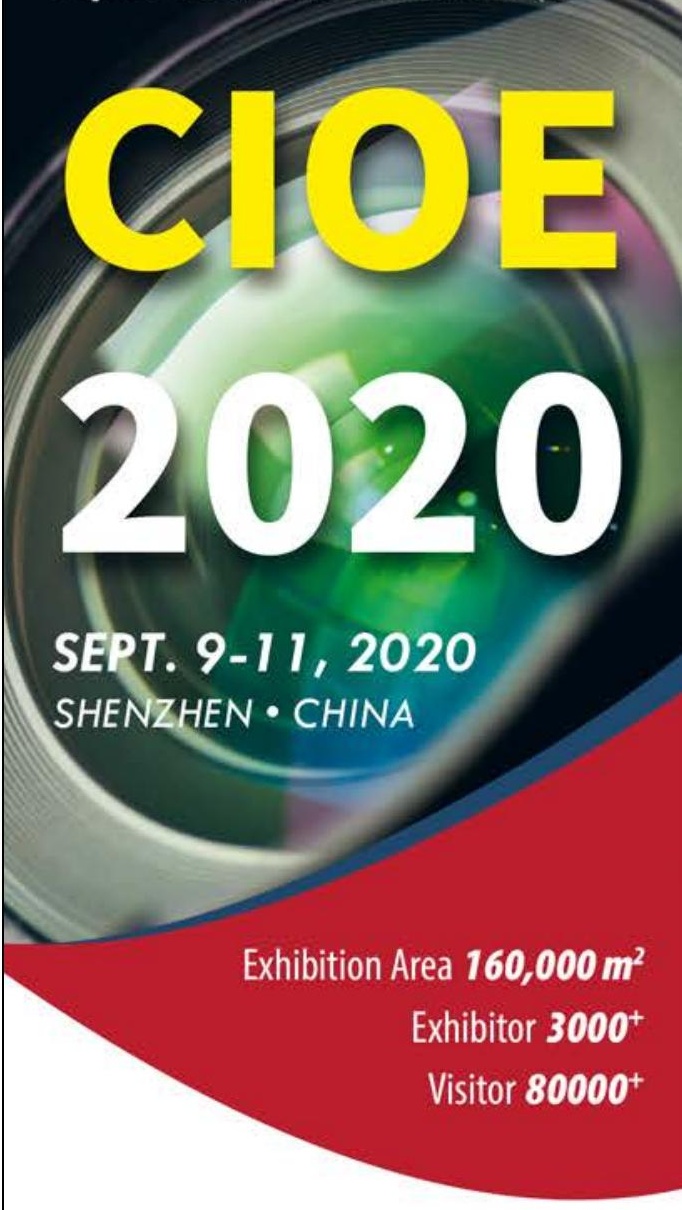

Presenting the Entire Optoelectronic Supply Chain

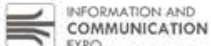

$$
\begin{aligned}
& \text { Expo } \\
& \text { - } \\
& \text { INETELGENT MANUFACCTURING }
\end{aligned}
$$

D)))

(3) IERESION OPTCS, M CAMERA MODULE
EXPO (9) OPTOEECTRONC

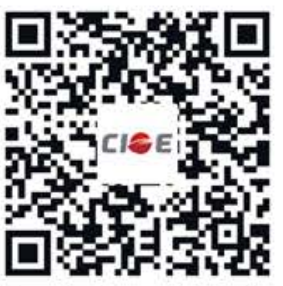

Scan For Free Admission 


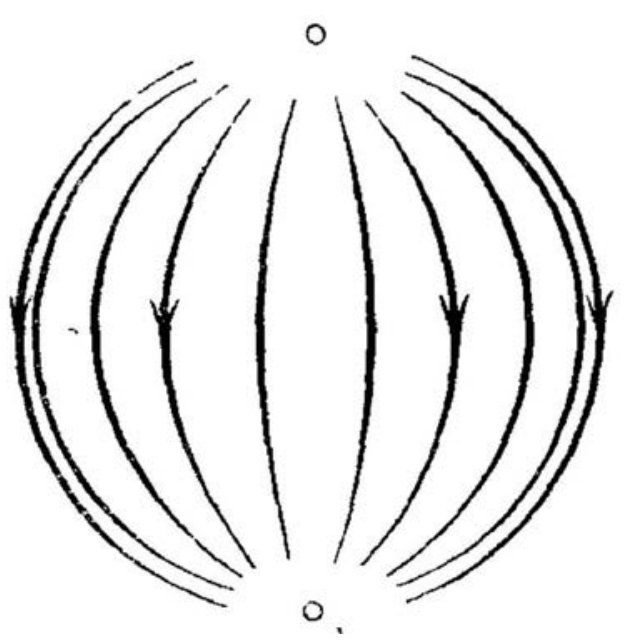

at TU Karlsruhe only a few years earlier, likely influenced Mie's [2] choice to specialize on the theoretical and technical applications of electrodynamics, culminating in his habilitation, "Draft of a general Theory of the Energy Transmission" in July 1897. Despite Mie's accomplishments in the practical and experimental domains, he provided a detailed mathematical solution of the Lecher line problem in 1900 that considers two parallel lines acting as a wave-guide to measure the wavelength of radio waves. This theoretical work played a pivotal role in establishing Mie's reputation as a theoretical physicist.

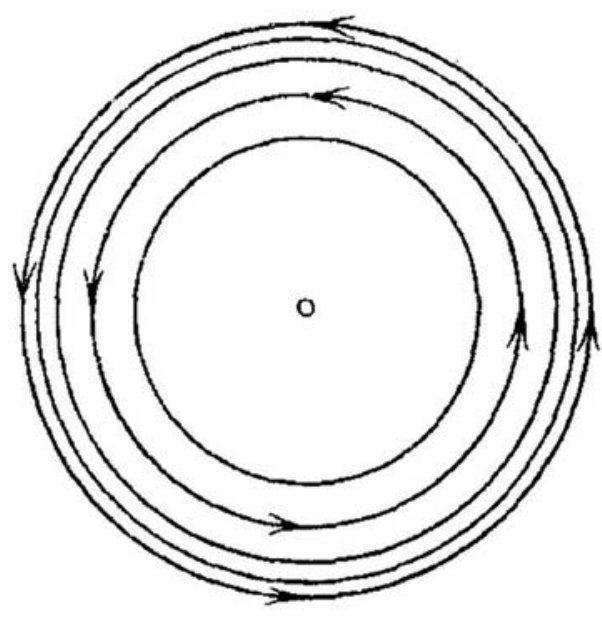

Figure 1.

Lines of the electric fields deduced from the expressions derived in Mie's seminal paper [1] for electric (left) and magnetic (right) dipoles. Adapted from Figs.[3-4] in Ref. [1].

Gustav Mie married Berta Hess in 1901, and shortly thereafter he obtained a special (extraordinarius) position of professor at the university of Greifswald, (1902-1917), another Hanseatic city in northeastern Germany. This period is the most productive of his career [2,3]. In particular, he made

\section{FAME OF MIE}

One reason for the enduring popularity of Mie's theory is that it supplies exact solutions to a highly non-trivial physics problem without forcing us to delve into the full details of its derivation. The famed 'Mie' coefficients $a_{n}$ and $b_{n}$ have relatively simple expressions in terms of what we now call the 'spherical Bessel functions', but which are hardly more difficult for a computer to calculate than the far better known sine and cosine functions (of which they are a generalization). The $a_{n}$ coefficients describe the 'electric multipole modes' of the sphere while the $b_{n}$ coefficients (denoted $p_{n}$ by Mie) describe its 'magnetic multipole modes' (the index $n=1$ stands for dipole, $n=2$ quadrupole, etc.).

These 'Mie' coefficients determine the entire field dynamics of any scattering process and mathematical manipulations à la Lorenz and Mie, and can extract information in terms of simple formulas. For example, the scattering cross section, $\sigma_{s}$, for light of wavelength $\lambda$ by any spherical particle can be calculated as:

$$
\sigma_{s}=\frac{\lambda^{2}}{2 \pi} \sum_{n}(2 n+1)\left[\left|a_{n}\right|^{2}+\left|b_{n}\right|^{2}\right]
$$

Given the vast range of applications of such simple formulas, it is no surprise that a host of extensions and generalizations have been proposed over the years to extend its range of applications as reviewed in box below: After Mie. 


\section{AFTER MIE}

Entire fields of study have formed around extensions of Mie theory. Quite naturally enough, Mie theory has been generalized to a wide class of special cases: spheroidal and cylindrically shaped particles, radially inhomogeneous spheres, chiral and anisotropic spheres, etc. Of particular note is the 'T-matrix' theory which uses Lorenz-Mie multipolar 'basis functions' to describe scattering by particles of arbitrary shapes, in which 'Mie theory' appears simply as a special case characterized by diagonal T-matrices [7]. Combining the T-matrix formulation with 'addition formulas' [8] and further analytic considerations [9], one can now solve multiple scattering solutions for finite clusters of particles on a computer, while other extensions add planar interfaces. Yet another domain of extensions has come to be called 'Generalized Lorenz-Mie theory' [10] (GLMT) since it 'generalizes' the incident plane waves of the initial Lorenz-Mie formulations to a host of exotic beam types which nowadays include localized sources, like atoms, modelled as electric or magnetic point-like multipolar emitters [11]. important contributions to problems related to the Poynting vector and energy transmission. He also developed a model of the interaction forces of atomic gases which was both a precursor and a more generalized form of the famed Lenard-Jones potential. Furthermore, Mie maintained an active correspondence with other renowned German physicists, notably with Max Planck on dispersion theory and later with Albert Einstein on questions of field theory.

\section{The enduring success of the "Mie" theory stems from its savant use of rigorous mathematical analysis to produce simple and powerful practical formulas which have found a vast array of applications, from atmospheric aerosols to nano-optics.}

IBS COATINGS For Optics Used With
High Power Lasers

\section{High Reflectivity Mirrors,} R $>99.9 \%$

LIDT > $50 \mathrm{~J} / \mathrm{cm}^{2} @ 1064 \mathrm{~nm}, 10 \mathrm{~ns}, 10 \mathrm{~Hz}$ LIDT > $3 \mathrm{~J} / \mathrm{cm}^{2} @ 1030 \mathrm{~nm}, 10$ ps, $20 \mathrm{kHz}$

$250 \mathrm{~mm}$ diameter

low GDD laser mirrors

for femtosecond applications

$\mathrm{R}>99.9 \%$ @ $720-880 \mathrm{~nm}$

\section{Thin Film Polarizers}

Contrast ratio $\mathrm{Tp} / \mathrm{Ts}>1000: 1$

\section{Dichroic Filters}

$\mathrm{R}>99.5 \%$ @ 1028-1080 nm and T > 99\%@ $980 \mathrm{~nm}$

$\mathrm{R}>99.9 \%$ @ $1064 \mathrm{~nm}$ and T > 99\% @ 808 nm

\section{Notch Filters}

OD 6.0 for $532 \mathrm{~nm}$

T>90\%@400-700nm

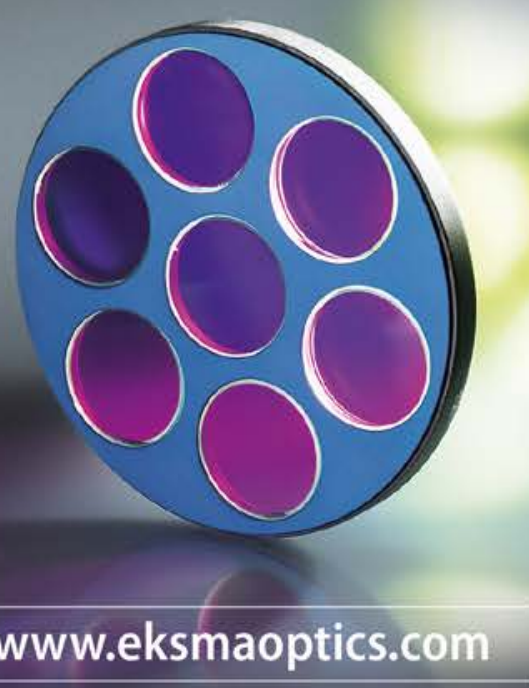

Representative in France:

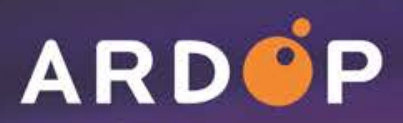

INDUSTRIE

Mie's interest in the theory of light scattering was clearly motivated by the Austrian-Hungarian chemist Richard Zsigmondy's work on the ultramicroscopic investigations of colloids for which he received the 1925 Nobel Prize in Chemistry. Gustav Mie set one of his students, Walter Steubing, to study the remarkable color effects observed in gold colloids. The results of these experiments, published separately, led Mie to develop his multipolar electromagnetic theory of light scattering by a spherical particle, humbly entitled 
"Contributions on the Optics of Turbid Media, particularly colloidal metal solutions".

In his theoretical work, G. Mie correctly explained the gold colloid colors as being due to what would come to be called, many decades later, structural colors based on localized surface plasmon resonances. Remarkably, and after thorough and technical mathematical derivations, G. Mie concludes his 69 long pages article with clear and didactic conclusions on the color of suspensions of colloidal gold particles, e.g. "The gold particles have in fact a very sharp maximum in the absorption capability in the green, and secondly a maximum in reflection capability in the yellow red. Very small particles reflect weakly and absorb strongly, consequently they make the solution ruby-red. Large particles reflect strongly, at the same time the pure absorption curve for them becomes lower and flatter, so they make the solution blue."

Although applications of Mie theory to plasmonics are important and continue to this day, its fame is also due to its host of successes in other domains, with the aerosol and rainbow problems being some of the best known. Issues of historical precedence aside, Mie's work 1908 was remarkable for being self-contained and mathematically extensive, with developments of asymptotic expansions for large spheres and numerical algorithms permitting the (laborious) calculation of the electromagnetic field distributions. Given the wealth of detail of this article and its orientation toward applications, it is of little wonder that when computers began to alleviate numerical burdens in the 1940s, it was to Mie's electromagnetic scattering formulation that so many turned, and in so doing, rendering multipolar scattering theory nearly inseparable from his name.

Mie's foray into scattering theory ended however in 1908. Keeping in mind that this was only three years after Einstein's 'Annus Mirabilis', it is hardly surprising that Gustav Mie turned his mathematical talents away from a specific ' $19^{\text {th' }}$ century problem to more general studies in field theory which embarked him on an ambitious program that attempted to formulate a unified theory of matter and radiation including ideas from both the burgeoning quantum mechanics and relativity. Mie's investigations along these lines are well documented, but are nowadays generally considered to be only of history interest. Mie's reputation was hardly tarnished by the failure of his unified matter-field program however, as he was an accomplished lecturer and well known for his experimental studies and thesis supervisions. Between 1917 and 1924, he occupied a professor position in experimental physics at the university of Halle. He spent the last part of his academic career at the university of Freiburg (1924-1935), in southwest Germany, where he remained after retirement. Mie carried out significant investigations on the unit problem where he developed a system of units (now fallen to disuse), and he authored a widely appreciated textbook on electricity and magnetism, the last of its multiple editions being authored by Mie when he was eighty years old [4].

The enduring success of the "Mie" theory stems from its savant use of rigorous mathematical analysis to produce simple and powerful practical formulas which have found a vast array of applications, from atmospheric aerosols to nano-optics. Gustav Mie passed away in 1957, three years after his beloved wife Berta. Neither Mie nor his contemporaries had considered his scattering paper to be of particular importance. However, given that he lived long enough to see the dawn of the computer era, he may well have remarked that one of his nearly forgotten publications, written nearly 50 years earlier, had begun its ascension to being crowned the 'hidden gem' of his long career.

\section{REFERENCES}

[1] G. Mie, Beiträge zur Optik trüber Medien, speziell kolloidaler Metallösungen, Ann. Phys. 330, 377-445 (1908)

[2] P. Lilienfeld, Gustav Mie: the person, Appl. Opt. 30, 4696-4698 (1991)

[3] H. Horvath, Gustav Mie and the scattering and absorption of light by particles:Historic developments and basics, J. Quant. Spectrosc. Radiat. Transfer 110, 787-799 (2009)

[4] G. Mie, Mehrbuch de Elektrizitat und des Megnestismus; Eine Experimentalphysik des Weltäthers für Physiker, Chemiker und Elektrotechniker, 736 S., Stuttgart 1910,2.vollständig umgearbeitete, Aufl. 1941, 3. Aufl. 1948, span. Ausgabe Barcelona 1944

[5] James Clerk Maxwell, Colours in metal glasses and in metallic Ims, Phil. Trans. R. Soc. Lond. A203, 385 (1904) and VII. Colours in metal glasses, in metallic films, and in metallic solutions. -II, r 205, 237-288 (1906)

[6] L. V. Lorenz, Lysbevægelsen i og uden for en af plane Lysbølger belyst Kugle, Detkongelige danske Videnskabernes Selskabs Skrifter 6, 1-62 (1890)

[7] M. I. Mishchenko, Comprehensive thematic T-matrix reference database: a 2017-2019 update, J. Quant. Spectrosc. Radiat. Transfer 242, 106692 (2019)

[8] L. Tsang, J. A. Kong, K.-H. Ding, C. O. Ao, Scattering of electromagnetic waves: numerical simulations, (John Wiley \& Sons), Vol 25 (2004)

[9] B. Stout, J. C. Auger, A. Devilez, Recursive T matrix algorithm for resonant multiple scattering: Applications to localized plasmon excitations", J. Opt. Soc. Am. A 25, 2549-2557 (2008)

[10] G.Gouesbet, G.Gréhan, Generalized Lorenz-Mie theories, (Berlin: Springer), vol. 31 (2011)

[11] B. Stout, A. Devilez, B. Rolly, N. Bonod, Multipole methods for Nano-antenna design, J. Opt. Soc. Am. B 28, 1213-1223 (2011) 